\title{
The EGPs: The Eclosion Hormone and Cyclic GMP-Regulated Phosphoproteins. I. Appearance and Partial Characterization in the CNS of Manduca sexta
}

\author{
David B. Morton and James W. Truman \\ Department of Zoology, University of Washington, Seattle, Washington 98195
}

The present study describes 2 phosphoproteins, both with an apparent molecular weight of $54 \mathrm{kDa}$, in the CNS of the tobacco hornworm, Manduca sexta. Their phosphorylation is regulated by a neuropeptide, eclosion hormone (EH), and the second messenger cGMP, which thus have been named the EGPs (eclosion hormone- and cGMP-regulated phosphoproteins). Although cAMP was more effective than cGMP at stimulating the phosphorylation of the EGPs in CNS homogenates, in the intact CNS CGMP was more effective. Since CGMP mediates the action of EH, this strongly suggests that CGMP is the second messenger that stimulates the phosphorylation of the EGPs in vivo.

The EGPs can only be phosphorylated in vitro during discrete time periods during the life of Manduca. During the larval and pupal molts, the EGPs can first be phosphorylated just prior to ecdysis. Their ability to be phosphorylated is correlated with the time when the insect is sensitive to EH. This close temporal correlation suggests that the ability to phosphorylate the EGPs determines when the insect can first respond to EH. During adult development, the EGPs first appeared on fluorograms $6 \mathrm{~d}$ before sensitivity to $\mathrm{EH}$, suggesting that at this stage other factors may also be involved in the regulation of sensitivity. For the ecdyses of all 3 stages, EH appeared to stimulate the phosphorylation of the EGPs at ecdysis.

The EGPs were found in all regions of the prepupal nervous system that were investigated, but only in the abdominal and pterothoracic ganglia of the developing adult. Fractionation of nervous system homogenates by ultracentrifugation revealed that one of the EGPs was present only in the pellet fraction, whereas the other was approximately equally distributed between pellet and supernatant. Furthermore, the EGPs in the pellet fraction could be partially solubilized with detergents and high salt concentrations.

In eukaryotic cells, the second messengers cAMP and cGMP exert most of their effects through the phosphorylation of specific proteins (see Nestler and Greengard, 1984). In the nervous sys-

\footnotetext{
Received May 15, 1987; revised Aug. 10, 1987; accepted Sept. 10, 1987.

We wish to thank R. Booker, S. F. Fahrbach, J. Gabriel, K. A. Mesce, L. M. Riddiford, B. A. Trimmer, and J. L. Witten for comments on the manuscript and many helpful discussions during the course of this work. We also wish to thank G. M. Terzi for preparation of the eclosion hormone. This work was supported by NIH Grant NS-13079.

Correspondence should be addressed to David B. Morton and James W. Truman, Department of Zoology, NJ-15, University of Washington, Seattle, WA 98185.

Copyright (C) 1988 Society for Neuroscience $0270-6474 / 88 / 041326-12 \$ 02.00 / 0$
}

tems of both vertebrates and invertebrates, many neurotransmitters, neuromodulators, and hormones exert their effects through the elevation of cyclic nucleotides (Lingle et al., 1982; Drummond, 1984) and, hence, through the phosphorylation of particular proteins (Nestler and Greengard, 1984).

In insects, the neuropeptide, eclosion hormone (EH), acts directly on the CNS to release the motor programs for the stereotyped ecdysis behavior (Truman, 1978a) and to activate stagespecific reflexes (Levine and Truman, 1983). These actions of $\mathrm{EH}$ are mediated through an increase in the intracellular levels of cGMP (Morton and Truman, 1985). Studies of EH action during pupal ecdysis of Manduca subsequently identified 2 proteins, both with an apparent molecular weight of 54,000 Da, which are phosphorylated in response to EH (Morton and Truman, 1986). These proteins were initially called "the $54 \mathrm{kDa}$ proteins," but are now referred to as the FGPs-the eclosion hormone- and cGMP-regulated phosphoproteins.

$\mathrm{EH}$ is released periodically during the life of Manduca to trigger the ecdyses of larval, pupal, and adult stages. In each case the nervous system is sensitive to the peptide only during the final few hours preceding ecdysis. Responsiveness is then lost at ecdysis and is only regained as the insect is undergoing the next molt. The study of pupal ecdysis showed a close correlation between the ability to phosphorylate the EGPs in vitro and the development of sensitivity to EH (Morton and Truman, 1986). The present paper further explores the relationship of the EGPs to EH action during pupal ecdysis and also at the larval and adult stages of the insect's life history.

\section{Materials and Methods}

Rearing and staging of animals. Larvae of the tobacco hornworm Manduca sexta were reared individually on an artificial diet (Bell and Joachim, 1978) at $26^{\circ} \mathrm{C}$ under a 17L:7D photoperiod. At the end of the terminal (fifth) larval stage the insect ceased to feed, emptied its gut, and entered the "wandering" stage. Pupal ecdysis occurred $4 \mathrm{~d}$ later. Once adult development was initiated, the animals were kept at $26^{\circ} \mathrm{C}$ with a 12L:12D photoperiod, with lights-off arbitrarily designated as 24:00. Adult ecdysis occurred 18-20 d later.

The timing of ecdysis of the fifth larval stage was predicted using external morphological markers, as described by Copenhaver and Truman (1982). These were the first appearence of pigmentation in the new mandibles ( $10 \mathrm{hr}$ before ecdysis) and the appearence of air in the old head capsule due to reabsorption of the molting fluid $(6 \mathrm{hr}$ beforc ecdysis). Events prior to pupal ecdysis were timed with reference to the pigmentation of a pair of sclerotized bars on the dorsal surface of the metathoracic segment ( $24 \mathrm{hr}$ before ecdysis) and to the resorption of molting fluid in the anterior segments ( $4 \mathrm{hr}$ before ecdysis; Truman et al., 1980). Animals at these stages will subsequently be referred to as $-24 \mathrm{hr}$ and $-4 \mathrm{hr}$ animals, respectively. As the timing of adult ecdysis is controlled by a circadian clock (Truman, 1978b), animals were taken 
at various times after "lights-on" (12:00) on the last day of adult development, with ecdysis occurring between 21:00 and 00:30 (Reynolds et al., 1979). For each experiment, parallel groups of animals were allowed to ecdyse and the timing of the experimental animals was judged relative to that of these controls.

Endogenous phosphorylation of homogenates. Nervous tissue was removed and homogenized in 50 mM HEPES buffer, 5 mM EDTA, $1 \mathrm{~mm}$ dithiothreitol (DTT), $\mathrm{pH} 7.0$, at a concentration of $1-1.5 \mathrm{mg}$ protein/ $\mathrm{ml}$ of buffer. The phosphorylation was carricd out by incubating $100 \mu \mathrm{l}$ of the homogenate with $40 \mu \mathrm{l} 250 \mathrm{~mm}$ HEPES buffer, pH 7.0,20 $\mu \mathrm{l} 100$ $\mathrm{mm} \mathrm{MgCl}, 20 \mu 11^{-5}$ м ATP containing $10 \mu \mathrm{Ci}$ gamma ${ }^{32} \mathrm{P}$-ATP (New England Nuclear; approximately $3000 \mathrm{Ci} / \mathrm{mmol}$ ), and $20 \mu \mathrm{l} \mathrm{cGMP,}$ cAMP, or water. The reaction was carried out at $30^{\circ} \mathrm{C}$ for $5 \mathrm{~min}$ and was started by the addition of the ATP and stopped with $200 \mu 120 \%$ trichloroacetic acid (TCA). The reaction mixture was allowed to stand on ice for $30 \mathrm{~min}$, centrifuged at $10,000 \times g$ for $5 \mathrm{~min}$ at $4^{\circ} \mathrm{C}$, and the pellet dissolved in $40 \mu \mathrm{l}$ sample buffer $[9.5 \mathrm{~m}$ urea, $2 \%$ Nonidet P40 (Sigma), 1.6\% Ampholines, pH 5-7, 0.4\% Ampholines, pH 3.5-10 (both LKB), 5\% 2-mercaptoethanol (2-ME), and $0.01 \%$ SDS]. The samples were left at room temperature overnight, vortexed, and centrifuged at $10,000 \times g$ for $5 \mathrm{~min}$ at $4^{\circ} \mathrm{C}$ and the supernatant separated by 2-dimensional SDS-PAGE, as described below.

Back-phosphorylation of the isolated CNS. $\Lambda$ bdominal nervous systems were dissected, leaving as much of the tracheal supply as intact as possible, and rinsed in Grace's insect medium (Gibco). The nervous systems were then placed in $0.5 \mathrm{ml}$ of Grace's medium in the presence or absence of $\mathrm{EH}$ and incubated at $26^{\circ} \mathrm{C}$ in a $95 \% \mathrm{O}_{2}-5 \% \mathrm{CO}_{2}$ atmosphere. Tissues were removed at the allotted time, homogenized and phosphorylated in vitro in the presence of $0.1 \mathrm{mM}$ cGMP and ${ }^{32} \mathrm{P}$-ATP, as described above. Any proteins phosphorylated as a result of incubation with EH would then be unavailable for phosphorylation by labeled phosphate and would be absent on the fluorograms.

The EH was partially purified from the corpora cardiaca-corpora allata complexes of pharate adult moths by passing an acidified methanol extract through a C-18 reverse-phase column using high-performance liquid chomatography. The concentration of $\mathrm{EH}$ was measured by bioassay, as described by Truman et al. (1980), immediately before use.

Separation and visualization of the proteins. The first dimension of separation was by nonequilibrium $\mathrm{pH}$ gradient electrophoresis (NEPHGE; O'Farrell et al., 1977), with gels containing $9.2 \mathrm{~m}$ urea, 4\% acrylamide, $2 \%$ Nonidet $\mathrm{P} 40$, and 2\% Ampholines, $\mathrm{pH}$ 3.5-10 (LKB). Samples of $40 \mu \mathrm{l}$ (approximately $120 \mu \mathrm{g}$ protein) were loaded onto the gels and run for $6 \mathrm{hr}$ at $500 \mathrm{~V}$, removed from the tubes, and equilibrated in $62.5 \mathrm{~mm}$ Tris- $\mathrm{HCl}$, pH $6.8,2.3 \%$ SDS, $10 \%$ glycerol, and $5 \% 2-\mathrm{ME}$. The second dimension was separated using SDS-PAGE (Laemmli, 1970) on $10 \%$ acrylamide gels containing $0.1 \%$ SDS, run at $50 \mathrm{~V}$ for $1 \mathrm{hr}$, then at $150 \mathrm{~V}$ until the tracking dye was $1 \mathrm{~cm}$ from the bottom of the gel. The gels were then silver-stained as described by Merril et al. (1983), dried, and exposed to preflashed Kodak XRP-1 film with DuPont Lightning plus intensification screens. The typical exposure time was $4 \mathrm{~d}$. The $M_{\mathrm{r}}$ standards used were phosphorylase B $(97,400)$, bovine albumin $(66,000)$, egg albumin $(45,000)$, glyceraldehyde-3-phosphate dehydrogenase $(36,000)$, carbonic anhydrase $(29,000)$, and trypsinogen $(24,000)$ (all Sigma). Isoelectric point markers used were trypsin inhibitor (4.55), human carbonic anhydrase B (6.57), and myoglobin (6.76 and 7.16) (all Sigma).

Densitometery of the fluorograms. The amount of label incorporated into the EGPs was estimated by scanning the fluorograms with a Quick Scan densitometer (Helena Laboratories). Only the more acidic of the EGPs (EGP-A) was scanned (Fig. $1 B$ ), and the area of the peak measured (half-height width $\times$ height) and compared to the area of the peak of a nearby phosphoprotein (at about $40 \mathrm{kDa}$; Fig. $1 A$, asterisk). The latter protein was chosen as an internal standard since its incorporation of label did not appear to change during the development of the insect nor in response to incubation with cyclic nucleotides (Fig. $1 B$ ). It should be noted that the relationship between the amount of label in the gel and the image density on the fluorogram is only linear at low image densities (Rudolph and Krueger, 1979). No attempt was made to expose fluorograms for different times to ensure nonsaturation, but as every comparison was made with fluorograms exposed for the same length of time, these comparisons provide a reasonable estimate of quantitative differences.

Measurement of cGMP levels. To determine the effect of EH on cGMP levels in various parts of the CNS, animals were injected with $\mathrm{EH} 4 \mathrm{hr}$ before pupal ecdysis or $2-4 \mathrm{hr}$ before adult ecdysis. Prepupae were injected with 0.5 units and pharate adults with 1 unit of EH dissolved in $25 \%$ acetonitrile $-75 \%$ insect saline (Ephrussi and Beadle, 1936). Controls were injected with solvent alone. The levels of cGMP in the CNS were determined as described by Morton and Truman (1985); their method is summarized briefly as follows: Fifteen minutes after injection, various parts of the CNS were removed and rapidly frozen in liquid nitrogen. The tissues were homogenized in ice-cold $1 \mathrm{M} \mathrm{HCl}-$ absolute ethanol $(1: 100)$, and the precipitated protein removed by centrifugation at $10,000 \times g$ at $4^{\circ} \mathrm{C}$ for $5 \mathrm{~min}$. The supernatant was evaporated and resuspended in $300 \mu \mathrm{l} 0.05 \mathrm{M}$ sodium acetate buffer, pH 6.2. Two $100 \mu \mathrm{l}$ aliquots were assayed using a cGMP radioimmunoassay kit (New England Nuclear). The sensitivity of the kit was increased by acetylating all of the samples using acetic anhydride prior to assay (Steiner et al., 1972).

Ultracentrifugation of CNS homogenates. Homogenates of the CNS were separated into soluble and particulate fractions to determine the location of the EGPs. Homogenates were phosphorylated (at 3 times normal volumes), the reaction stopped by cooling on ice, and then were centrifuged at $100,000 \times g$ at $2^{\circ} \mathrm{C}$ for $1 \mathrm{hr}$. The protein in the supernatant was precipitated by the addition of $600 \mu \mathrm{l} 20 \% \mathrm{TCA}$, and the pellet fraction dissolved in $40 \mu \mathrm{l}$ sample buffer. The proteins were separated by 2 -dimensional SDS-PAGE, as described above.

Photoaffinity labeling of cAMP-binding proteins. cAMP-binding proteins present in homogenates were identified by photoaffinity labeling with 8-azido cAMP according to the methods of Walter and Greengard (1983). Nervous tissue was homogenized in $50 \mathrm{~mm} 2-(N$-morpholino)ethanesulfonic acid (MES) buffer, $\mathrm{pH} \mathrm{6.2,} \mathrm{containing} 1 \mathrm{mM}$ IBMX, $10 \mathrm{mM} \mathrm{MgCl}_{2}$, and $0.5 \mathrm{~mm} 2-\mathrm{ME}$, at a concentration of about $1 \mathrm{mg} / \mathrm{ml}$ and $80 \mu \mathrm{l}$, incubated with $10 \mu \mathrm{l}$ of $10 \mu \mathrm{M}{ }^{32} \mathrm{P}-8$-azido cAMP (ICN; 71 $\mathrm{Ci} / \mathrm{mmol}$ ) in the presence or absence of $10 \mu \mathrm{l}$ of $5 \times 10^{-4} \mathrm{M} \mathrm{cAMP}$, both dissolved in the same buffer for $1 \mathrm{hr}$ in the dark. The samples were then exposed to UV light at $254 \mathrm{~nm}$ using a Minerallight UVG-11 lamp (Ultraviolet Products) placed $10 \mathrm{~cm}$ above the samples. The reaction was stopped and the proteins separated by 2 -dimensional SDS-PAGE.

\section{Results}

\section{Phosphorylation of the EGPs in CNS homogenates in the presence of $C G M P$ and $C A M P$}

Figure $1 A$ gives an example of a portion of a fluorogram that shows the phosphorylation of the 2 EGPs in response to the addition of $0.1 \mathrm{mM}$ cGMP to a cell-free CNS homogenate. The incorporation of phosphate into the EGPs was estimated by measuring the density of the EGP-A. The path used in the scan also measured the density of a $40 \mathrm{kDa}$ protein whose phosphorylation was cyclic nucleotide-independent, and of a $36 \mathrm{kDa}$ protein whose phosphorylation was dependent on cyclic nucleotide levels (Fig. $1 B$ ). As the incorporation of label into the $40 \mathrm{kDa}$ protein was not cyclic nucleotide-dependent, it was used as a standard for comparing the incorporation of label into the EGPs.

The effect of various concentrations of cAMP and cGMP on the incorporation of labeled phosphate into EGP-A is shown in Figure 2. cAMP was more effective than cGMP at stimulating the phosphorylation of the EGPs in CNS homogenates. The concentration of cAMP needed to stimulate half-maximal phosphorylation of the EGPs was $0.2 \mu \mathrm{M}$, compared to $36 \mu \mathrm{M}$ for cGMP. Both cyclic nucleotides stimulated the same maximal level of phosphorylation. Other cyclic nucleotide-stimulated phosphoproteins, such as the $36 \mathrm{kDa}$ protein, showed a similar dose-response relationship, with cAMP being more effective than $\mathrm{cGMP}$.

\section{Time course of EGP phosphorylation in the isolated CNS}

In a previous report (Morton and Truman, 1986) we showed, by using the back-phosphorylation technique of Forn and Greengard (1978), that the injection of EH into prepupae stimulated the phosphorylation of the EGPs. To show that this phos- 

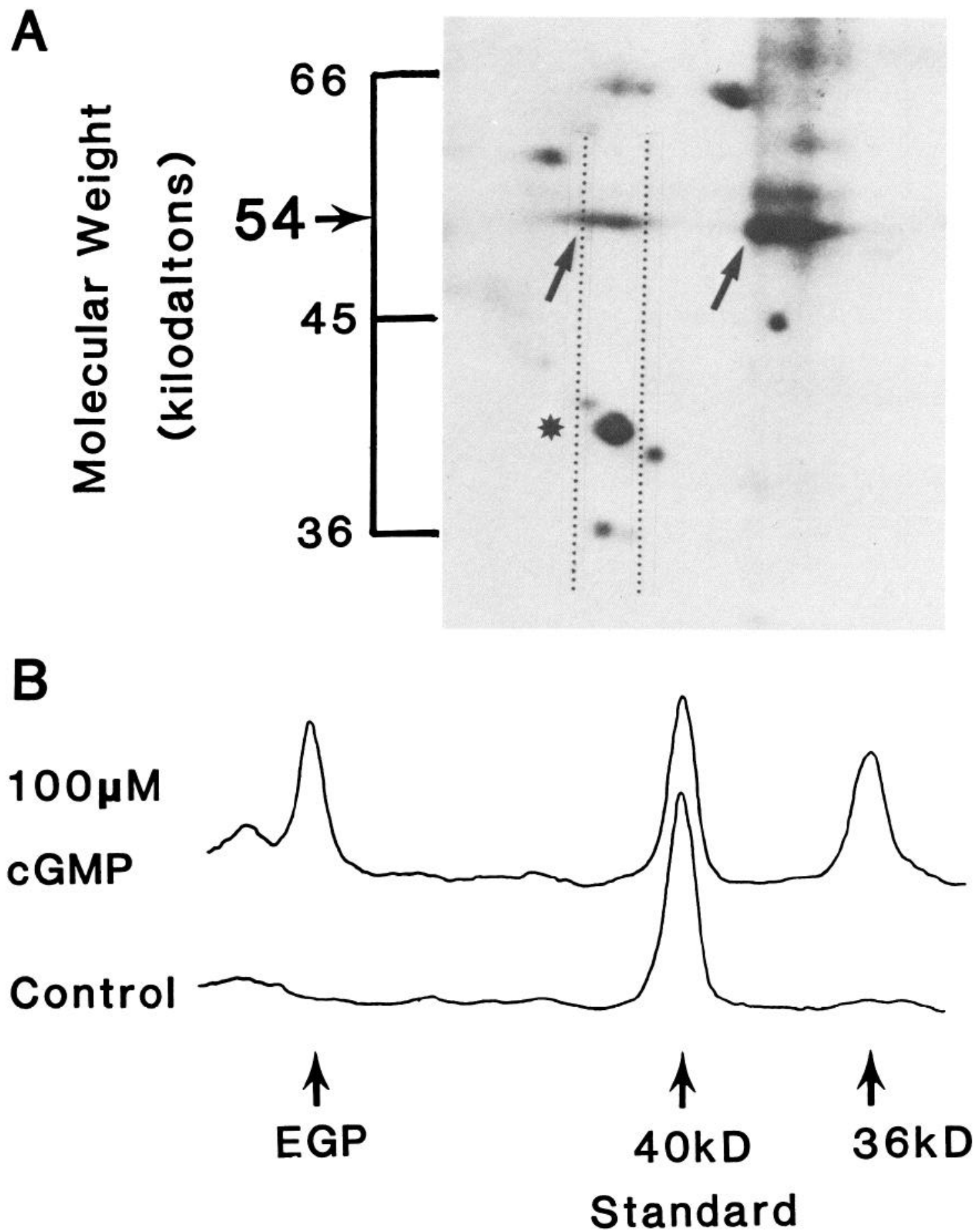

Figure 1. Estimation of the incorporation of label into the EGPs. $A$, Portion of a fluorogram showing the region scanned with the densitometer. In this and subsequent figures, the portion of the fluorogram shown covers the molecular-weight range of about $70-30 \mathrm{kDa}$ and the isoelectric point range of 5.0 (left) and 7.0 (right). The 2 EGPs are marked with arrows and the density of the more acidic EGP (EGP-A) measured relative to the standard phosphoprotein at $40 \mathrm{kDa}$, which is marked with an asterisk. B. Examples of densitometer scans from fluorograms made from abdominal nervous system homogenates incubated in the presence or absence of $100 \mu \mathrm{M}$ cGMP. The peaks corresponding to EGP-A, the $40 \mathrm{kDa}$ standard phosphoprotein and the $36 \mathrm{kDa}$ phosphoprotein are marked with arrows. The area of the EGP peak was then measured relative to the area of the $40 \mathrm{kDa}$ peak.

phorylation was due to the direct action of $\mathrm{EH}$ on the CNS, we removed the abdominal nervous systems from $-4 \mathrm{hr}$ animals and incubated them for $1 \mathrm{hr}$ in the presence or absence of 1 $\mathrm{U} / \mathrm{ml}$ of $\mathrm{EH}$. After incubation, the nervous tissue from the 2 groups was homogenized and incubated with ${ }^{32} \mathrm{P}-\mathrm{ATP}$ in the presence of $0.1 \mathrm{~mm}$ cGMP. Nervous tissue incubated in the presence of EH showed no incorporation of label into the EGPs (Fig. 3). Controls incubated without hormone showed the normal phosphorylation patterns. The lack of label in the former was presumed to be the result of the EGPs' being phosphorylated 
with unlabeled phosphate in response to EH exposure. The EGPs were the only proteins that consistently showed a lack of labeling after intact nervous tissue was incubated in the presence of EH. For example, in Figure $3 \mathrm{~A}$ the $36 \mathrm{kDa}$ protein (asterisk) showed the same level of incorporation whether or not the CNS was exposed to $\mathrm{EH}$.

The specificity of the action of $\mathrm{EH}$ in phosphorylating only the EGPs was also scen when nervous tissue from $-24 \mathrm{hr}$ animals was incubated in the presence or absence of EH. At this stage the EGPs are presumed absent from the CNS (Morton and Truman, 1986), but EH will elevate cGMP levels (Morton and Truman, 1985). Inspection of fluorograms showed no detectable changes in the incorporation of labeled phosphate into proteins from these samples that resulted from exposure to $\mathrm{EH}$ (results nol shown).

At pupal ecdysis, when $-4 \mathrm{hr}$ animals are injected with $\mathrm{EH}$, the latency to ecdysis is inversely related to hormone dosage, with a minimum latency of about 50 min (Truman et al., 1980). Prepupae injected with a maximal dosage of $\mathrm{EH}$, however, show an increase in cGMP within 5 min (Morton and Truman, 1985). When nervous tissue is incubated in a high concentration of $\mathrm{EH}$ (1 $\mathrm{U} / \mathrm{ml}$ ), the EGPs are completely phosphorylated by $60 \mathrm{~min}$ (Fig. 3A). At lower hormone concentrations $(0.25 \mathrm{U} / \mathrm{ml})$, the time taken for phosphorylation of the EGPs is longer (as measured by the reduced incorporation of labeled phosphate into homogenates; Fig. $3 B$ ). Thus, as is seen with the behavioral latency, the rate at which the EGPs are phosphorylated also appears to be a function of the amount of EH that is added.

The use of the isolated abdominal CNS also enabled us to test the relative abilities of cAMP and CGMP to stimulate the phosphorylation of the EGPs in the intact CNS. Abdominal nervous systems were incubated in various concentrations of cGMP and cAMP for $1 \mathrm{hr}$ and then subjected to in vitro phosphorylation, as above. At $1 \mathrm{~mm}$, both CGMP and cAMP stimulated complete phosphorylation of the EGPs, so that no labeled phosphate was incorporated into the EGPs during the subsequent in vitro phosphorylation (Fig. 4). At lower concentrations, cGMP was consistently more effective than cAMP in stimulating the endogenous phosphorylation of the EGPs, with cGMP showing an $\mathrm{ED}_{50}$ of about $0.1 \mu \mathrm{M}$, whereas that of CAMP was $4 \mu \mathrm{M}$. Thus, although cAMP was more effective than cGMP at stimulating the phosphorylation of the EGPs in cell-free homogenates, the reverse relationship was seen when the intact CNS was exposed to the cyclic nucleotides.

The EGPs were the only proteins detected whose phosphorylation was stimulated more effectively by cGMP than by cAMP in the intact CNS. The $36 \mathrm{kDa}$ protein was also phosphorylated in the isolated CNS in response to cyclic nucleotides. Unlike the case with the EGPs, however, cAMP was more effective than CGMP in stimulating its phosphorylation. Incubation of nervous systems for $1 \mathrm{hr}$ with $1 \mathrm{~mm}$ cAMP resulted in a reduction of $51 \pm 17 \%$ (mean $\pm \mathrm{SEM} ; n=3$ ) in the incorporation of label into the $36 \mathrm{kDa}$ protein during subsequent in vitro phosphorylation, whereas the same levels of cGMP were ineffective (reduction of $7 \pm 10 \%$ ).

\section{Temporal pattern of appearance of the EGPs during the life history of Manduca}

EH triggers larval, pupal, and adult ecdyses in Manduca (Truman, 1971; Truman et al., 1980; Copenhaver and Truman, 1982). If the EGPs are involved in the action of EH in triggering

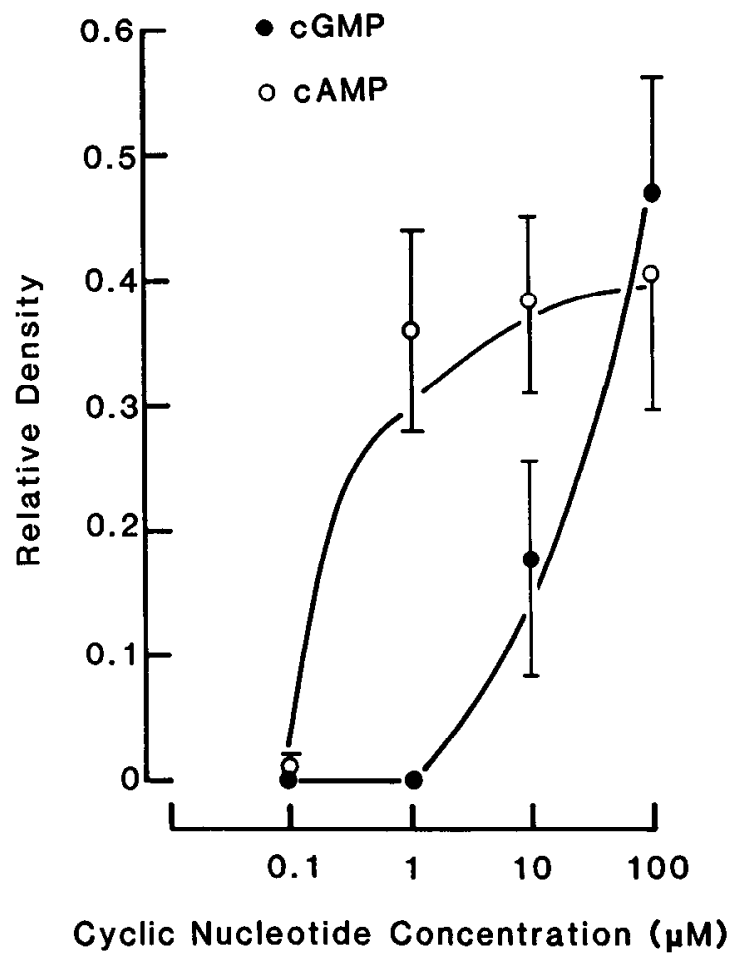

Figure 2. A, Effect of CGMP and cAMP on the phosphorylation of the EGPs in homogenates of the abdominal nervous system of Manduca. Abdominal nervous systems from prepupae, $4 \mathrm{hr}$ before ecdysis, were homogenized and incubated with ${ }^{32} \mathbf{P}$-ATP in the presence of various concentrations of cAMP and cGMP. The proteins were separated by 2D SDS-PAGE and fluorograms of the gels made. The incorporation of labeled phosphate into EGP-A was estimated as described in the legend to Figure 1. Each point represents the mean \pm SEM of 3 determinations.

ecdysis, then they should be present prior to each ecdysis, irrespective of the stage in the insect's life history.

Figure $5 A$ shows the temporal relationship between the incorporation of labeled phosphate into the EGPs in the abdominal nervous system and the behavioral sensitivity to EH during the fifth larval and pupal molts. During the last larval molt, behavioral sensitivity to EH begins at about $6 \mathrm{hr}$ prior to ecdysis (Copenhaver and Truman, 1982). When abdominal nervous systems were taken from molting larvae at this stage and subjected to in vitro phosphorylation, we found a very low level of incorporation of label into the EGPs. Two hours later, the EGPs wcre clcarly labeled and, after another $2 \mathrm{hr}$, the density was even greater. Approximately $2 \mathrm{hr}$ later, the larvae had released $\mathrm{EH}$ and were undergoing ecdysis; extracts of the nervous tissue taken at this time no longer showed incorporation of phosphate into the EGPs. This abrupt disappearance of the ability to label these proteins with exogenous phosphate was presumed to be due to endogenous EH's having stimulated their phosphorylation with endogenous unlabeled phosphate.

Following ecdysis, no incorporation of labeled phosphate into the EGPs was detected during the feeding stage of the fifth instar, the wandering stage, and most of the prepupal period (a period of $7 \mathrm{~d}$ ). The absence of labeling of the EGPs was correlated with the fact that insects are not responsive to EH during this period. Both behavioral sensitivity and the ability to label the EGPs reappeared $8 \mathrm{hr}$ before pupal ecdysis (Morton and Truman, 1986). As in larval ecdysis, the onset of pupal ecdysis behavior 

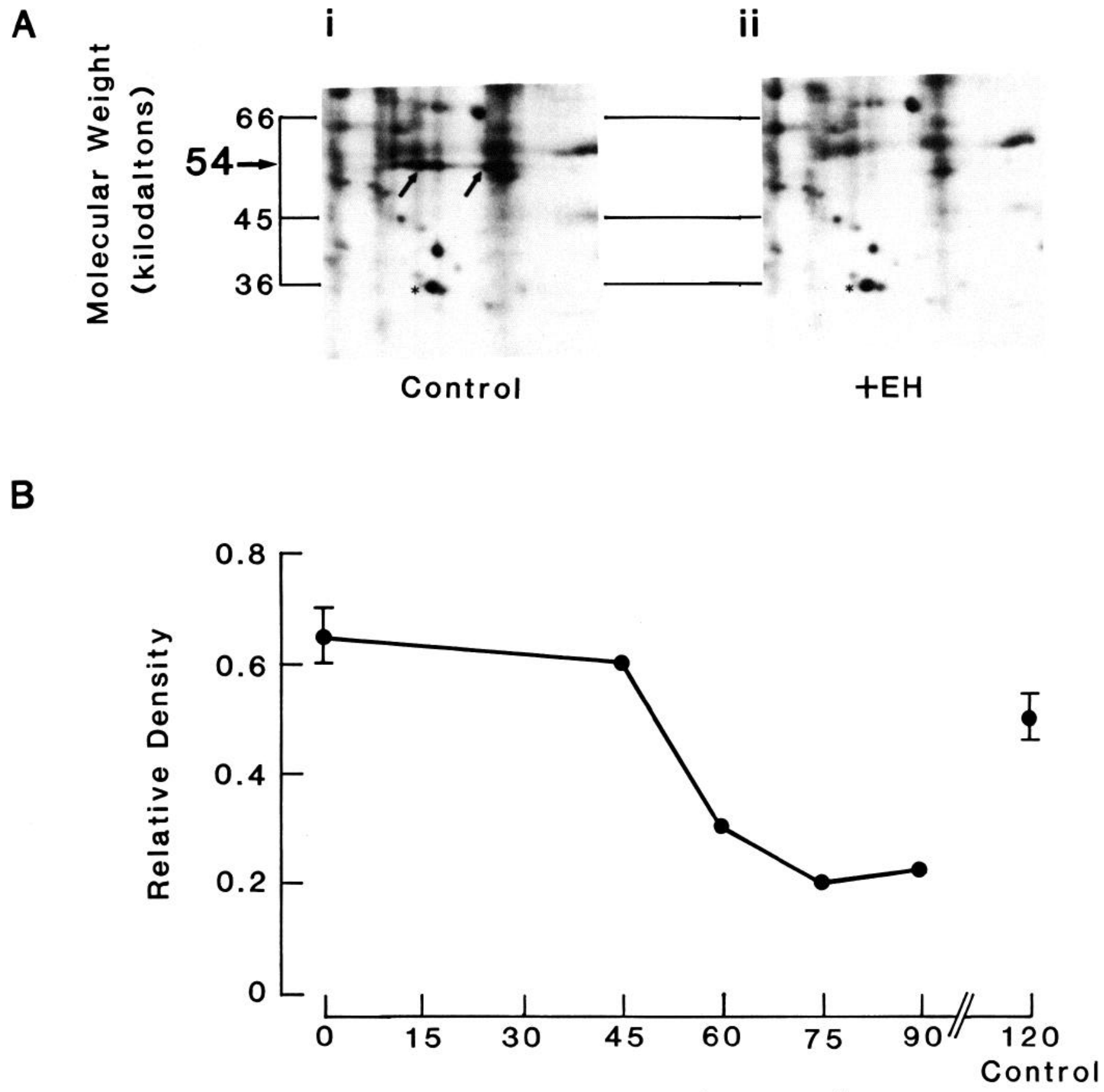

Incubation Time (minutes)

Figure 3. Back-phosphorylation of the EGPs in the intact, isolated CNS by EH. A, Example of fluorograms made from the abdominal nervous systems from $-4 \mathrm{hr}$ prepupae that were incubated in culture in the presence or absence of $1 \mathrm{U} / \mathrm{ml}$ of EH for $1 \mathrm{hr}$. After incubation, the nervous systems were homogenized ( 2 nervous systems per sample) and phosphorylated with ${ }^{32} \mathrm{P}-\mathrm{ATP}$ in the presence of $0.1 \mathrm{~mm}$ cGMP. The proteins were separated by 2D SDS-PAGE and fluorograms made. The 2 EGPs are marked with arrows in the control fluorogram $(i$; incubated in the absence of EH), but are absent after incubation in $1 \mathrm{U} / \mathrm{ml}$ of EH (ii). $B$, Time course of phosphorylation of the EGPs in nervous systems that were exposed to 0.25 units of $\mathrm{EH} / \mathrm{ml}$ for various intervals before homogenization and in vitro phosphorylation in the presence of $0.1 \mathrm{mM}$ cGMP. The incorporation of labeled phosphate into the EGPs was estimated as described in Figure 1. Controls represent nervous systems that were incubated in the absence of $\mathrm{EH}$ for $2 \mathrm{hr}$. Each time point represents data from one sample ( 2 nervous systems), except for the control and 0 time points, which represent the mean and range of 2 samples.

marked the abrupt disappearance of the ability to incorporate phosphate into the EGPs.

We encountered some difficulty in reliably detecting the EGPs in the abdominal nervous system of pharate adult Manduca.
This was because this tissue contained more protein at this stage ( $210 \mu \mathrm{g}$, compared to $176 \mu \mathrm{g}$ for prepupae) because of the presence of the "dorsal pad" of connective tissue. The presence of another phosphoprotein at about $57 \mathrm{kDa}$ partially obscured the 


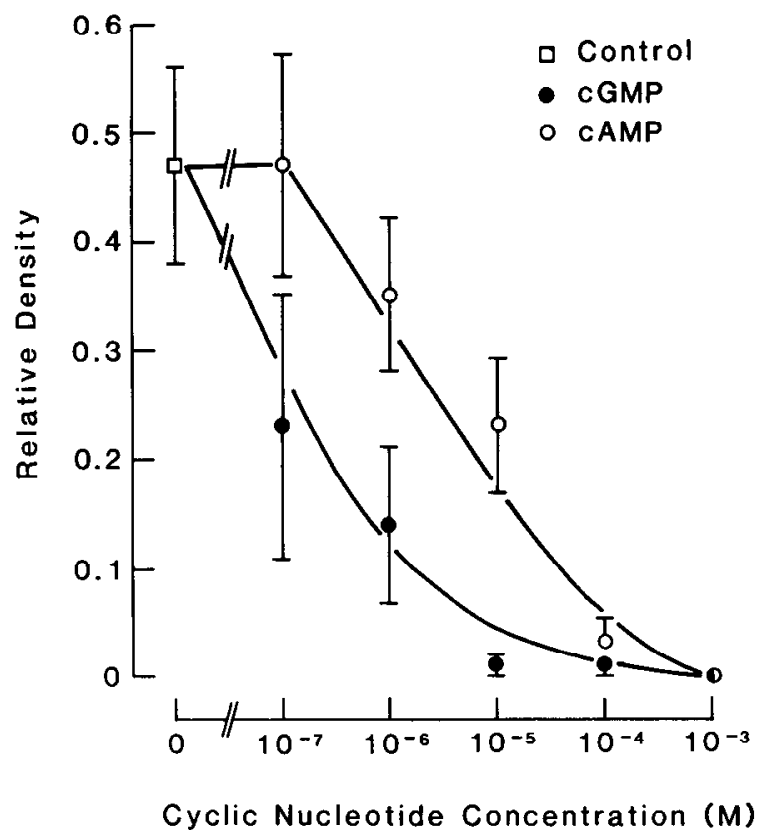

Figure 4. Comparison of the ability of cGMP and cAMP to induce the phosphorylation of the EGPs in the isolated abdominal CNS. Nervous systems from $-4 \mathrm{hr}$ prepupae were incubated for $1 \mathrm{hr}$ in various concentrations of cGMP and cAMP. Nervous systems (2 per sample) were then homogenized and phosphorylated with ${ }^{32} \mathrm{P}$-ATP in the presence of $0.1 \mathrm{mM}$ cGMP. The proteins were separated by 2D SDS-PAGE and fluorograms made. The incorporation of labeled phosphate into the EGPs was estimated as described in Figure 1. Each point represents the mean \pm SEM of 3 samples.

EGPs and made it difficult to reliably detect their presence (see Fig. 6). To partially overcome this problem we phosphorylated abdominal nervous system homogenates and then centrifuged them at $100,000 \times g$ for $1 \mathrm{hr}$. The proteins present in the supernatant were then separated by SDS-PAGE. As detailed below for the prepupal CNS, only EGP-A was present in the supernatant fraction, and this was used as a marker for the presence of both EGPs at this stage.

The time course of the appearance of $\mathrm{EH}$ sensitivity and the ability to label EGP-A in the abdominal nervous system of the developing adult are shown in Figure $5 B$. The presence of the $57 \mathrm{kDa}$ protein made densitometric quantification of EGP-A during adult development unreliable (see Fig. 6), so the level of incorporation of label into EGP-A at various times was judged subjectively and plotted relative to the incorporation seen at 3 hr before ecdysis. Behavioral sensitivity to EH was first clearly seen between 6 and $8 \mathrm{hr}$ before ecdysis. Abdominal nervous systems taken from animals at this time and at times closer to ecdysis showed the presence of EGP-A. As with larval and pupal ecdysis, abdominal nervous systems removed from animals just after adult ecdysis no longer showed incorporation of label into EGP-A. This suggests that EH also stimulated the phosphorylation of the EGPs at adult ecdysis. Unlike in larvae and pupae, however, incorporation of label into EGP-A was clearly seen at times when developing adults were not behaviorally sensitive to $\mathrm{EH}$. They could first be labeled as early as $6 \mathrm{~d}$ before ecdysis. Another unusual feature of adult ecdysis was that at $24 \mathrm{hr}$ after ecdysis, EGP-A was again able to incorporate label.

Figure 6 shows the results of an experiment to determine whether EH treatment of developing adults stimulates the phosphorylation of EGP-A at times when EH will not trigger ecdysis
A
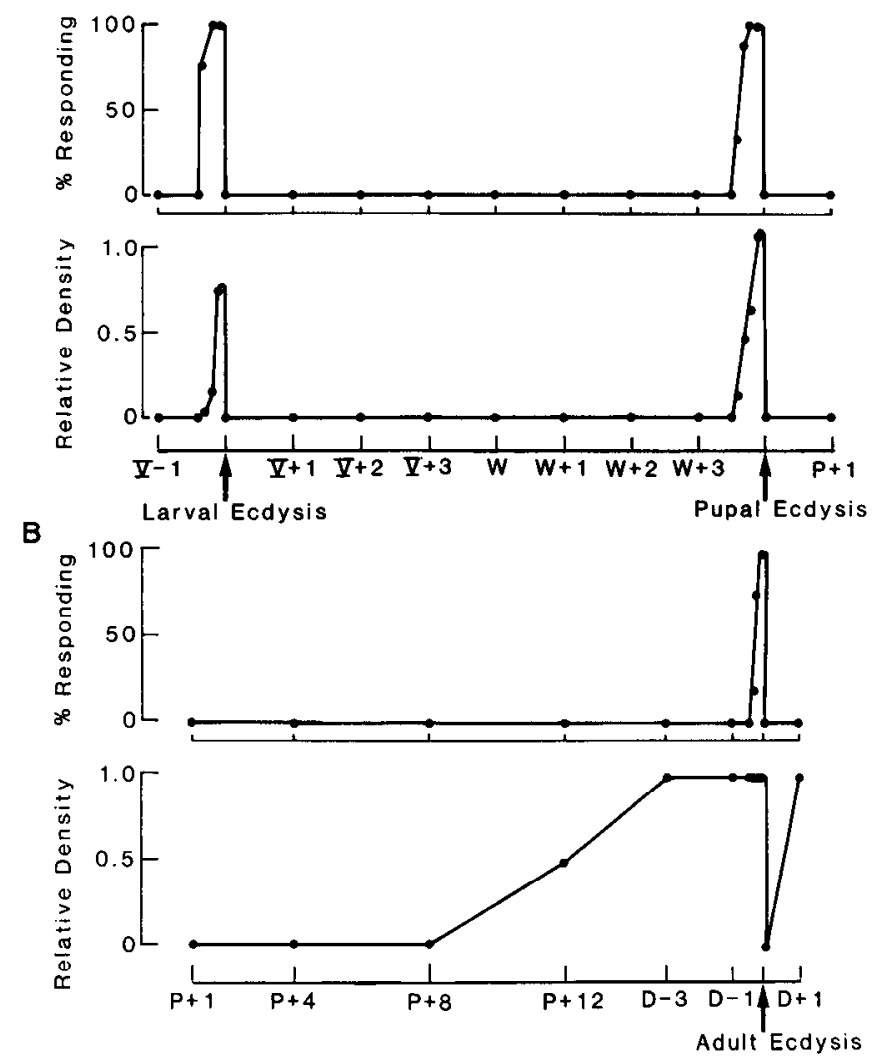

Figure 5. Time course of appearance of the EGPs relative to the timing of sensitivity to eclosion hormone during development. Upper panels represent the development of eclosion hormone sensitivity. Animals were injected at various times with $\mathrm{EH}$, and the percentage of animals that showed premature ecdysis behavior noted. Data redrawn from Copenhaver and Truman (1982), Morton and Truman (1986), and Reynolds et al. (1979). Lower panels represent the presence of the EGPs during development. Abdominal nervous systems were removed and homogenized at various times during development, phosphorylated with 32P-ATP in the presence of $0.1 \mathrm{mM}$ CGMP, and the proteins separated by $2 D$ SDS-PAGE. In the case of developing adults, the homogenate was centrifuged at $100,000 \times g$ for $1 \mathrm{hr}$ at $2^{\circ} \mathrm{C}$ and only the supernatant fraction was separated by 2D SDS-PAGE. Fluorograms of the gels were made and the incorporation of labeled phosphate into the EGPs was estimated as described in Figure 1 for larval and pupal ecdysis. For adult ecdysis, the relative incorporation of label was judged subjectively relative to the incorporation seen $3 \mathrm{hr}$ before ecdysis. A score of 0 indicates that no incorporation of label into the EGPs could be detected, while a score of 1 indicates that incorporation was approximately equal to that seen at $-3 \mathrm{hr}$. $A$, Larval and pupal development. Each day of development is marked relative to 3 developmental markers: the ecdysis into the fifth larval instar $(V)$, wandering $(W)$, and pupal ecdysis $(P) . B$, Adult development. Each time point represents either days after pupal ecdysis $(P)$ or days before or after adult ecdysis $(D)$.

behavior. Animals at $28 \mathrm{hr}$ before ecdysis will not respond to $\mathrm{EH}$, whereas $6 \mathrm{hr}$ before ecdysis they will respond to $\mathrm{EH}$ by initiating ecdysis $3.5 \mathrm{hr}$ after injection. Animals were taken at 28 and $6 \mathrm{hr}$ before adult ecdysis and injected with 1 unit of EH or saline; their abdominal CNS was then removed $3.5 \mathrm{hr}$ later. Figure 6 shows that in both the -28 and -6 hr groups, EGP-A no longer incorporated labeled phosphate in the EH-treated insects. This indicates that although $\mathrm{EH}$ does not trigger ecdysis behavior $28 \mathrm{hr}$ before the normal time, it stimulates the phosphorylation of the EGPs. As expected from this result, EH also stimulated an increase in cGMP levels in the CNS of $-28 \mathrm{hr}$ 


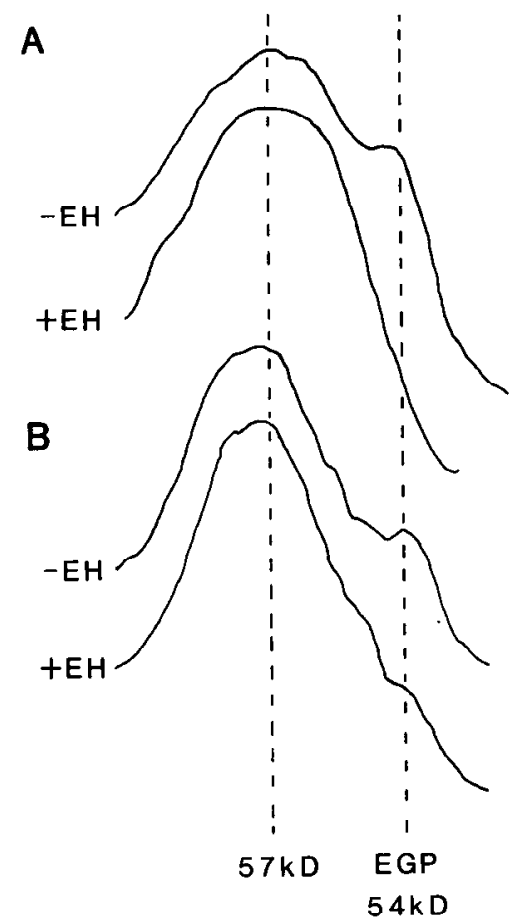

Figure 6. Back-phosphorylation of the EGPs in developing adult Manduca by EH. Animals were selected 28 and $6 \mathrm{hr}$ before adult ecdysis and each group injected with either 1 unit of EH in $50 \mu l$ saline or with $50 \mu \mathrm{l}$ of saline alone. Abdominal nervous systems were then removed $3.5 \mathrm{hr}$ later (the time taken for the EH-injected $-6 \mathrm{hr}$ animals to ecdyse), homogenized, and phosphorylated with ${ }^{32} \mathrm{P}$-ATP in the presence of 0.1 mM cGMP. All the samples were then centrifuged at $100,000 \times g$ for $1 \mathrm{hr}$ at $2^{\circ} \mathrm{C}$, and the proteins present in the supernatant separated by 2D SDS-PAGE. Fluorograms were made and the portion containing EGP-A scanned with a densitometer. In each case, the upper trace is from animals injected with saline, showing the normal incorporation of label into EGP-A; the lower trace is from animals injected with EH, showing the lack of incorporation of label. Note that in the developing adult, EGP-A appears as a shoulder on a larger peak at $57 \mathrm{kDa}$, as opposed to a discrete peak in the prepupal CNS (Fig. $1 B$ ). $A$, Densitometer scans made from abdominal nervous tissue from $-28 \mathrm{hr}$ animals. $B$, Densitometer scans made from abdominal nervous tissue from $-6 \mathrm{hr}$ animals. Each sample contained the pooled nervous tissue from 4 animals.

animals (156 $\pm 19 \%$, as compared to control-injected animals; mean $\pm \mathrm{SEM}, n=8)$.

\section{Spatial distribution of the EGPS in the prepupal and pharate adult $C N S$}

The distribution of the EGPs in various parts of the prepupal ( $4 \mathrm{hr}$ before ecdysis) CNS is shown in Table 1. EH stimulated an elevation of cGMP in the 3 regions of the CNS that were examined. Likewise, these 3 regions also contained the EGPs. As with the abdominal nervous system, the brains and thoracic ganglia removed from ecdysing pupae showed no incorporation of label into the EGPs. This suggests that the EGPs in these regions of the CNS are also phosphorylated endogenously at the time of ecdysis. Also, the presence of the EGPs is not restricted to cell somata, as they were found in both the abdominal ganglia and the abdominal connectives when these were separated by dissection and homogenized and incubated separately (results not shown).

In the pharate adult, the EGPs were clearly seen in the $100,000 \times g$ supernatant fraction of the abdominal nervous system and also in the fused pterothoracic ganglion (total homogenates). In pterothoracic ganglia removed from moths that had just ecdysed, as in the abdominal nervous system, the EGPs no longer accepted labeled phosphate. The EGPs were also seen in the pterothoracic ganglion $24 \mathrm{hr}$ before ecdysis, when the animals were not behaviorally sensitive to EH. We found no definitive evidence for the presence of the EGPs in the prothoracic ganglion or the brain. This inability was partly duc to the presence of a $57 \mathrm{kDa}$ protein, similar to the one found in the abdominal nervous system, which may have obscured low levels of labeling in the $54 \mathrm{kDa}$ region. In some fluorograms, very faint labeling was seen in the $54 \mathrm{kDa}$ region, but we could not be confident as to whether this was due to low levels of the EGPs or to smearing of the $57 \mathrm{kDa}$ protein.

\section{Distribution of the EGPs in subcellular fractions}

Figure 7 shows the distribution of the EGPs in the supernatant and pellet fractions after centrifugation at $100,000 \times \mathrm{g}$. In homogenates of abdominal nervous tissue from $-4 \mathrm{hr}$ prepupae, which had been phosphorylated and then centrifuged, EGP-A was found in both the soluble and particulate fractions, whereas the more basic EGP (EGP-B) was found only in the particulate fraction (Fig. 7, $A, B$ ). In one series of experiments the homogenate was centrifuged before phosphorylation, the pellet resuspended in homogenization buffer, and both fractions phosphorylated independently in the presence of $0.1 \mathrm{mM}$ cGMP. No label was incorporated into the EGPs in the pellet fraction, presumably because the Manduca G-kinase was present only in the soluble fraction of homogenates, as has been shown for mammalian G-kinase (Lincoln and Corbin, 1983). Phosphorylation reactions carried out on the supernatant resulted in phosphorylation of EGP-A only, but the amount of label incorporated into it was less than when the homogenate was phosphorylated before centrifugation. This reduction in labeling could be due to the existence of some factor in the $100,000 \times g$ pellet fraction that enhanced the phosphorylation reaction. Alternatively, it could be caused by the fact that the phospho-EGP-A is more soluble than the dephospho-EGP-A.

To demonstrate that the EGPs were in fact present in the pellet fraction, we rehomogenized the pellet with the $100,000 \times$ $g$ supernatant taken from CNS homogenates from $-24 \mathrm{hr}$ animals (the EGPs are presumed absent at this time). This mixture was then phosphorylated in the presence of $0.1 \mathrm{~mm} \mathrm{cGMP}$ and again separated by $100,000 \times g$ centrifugation for $1 \mathrm{hr}$. Fluorograms of both fractions revealed the presence of both EGP$A$ and EGP-B in the $100,000 \times g$ pellet and also very low levels of EGP-A in the supernatant fraction. $\Lambda$ s EGP-A was not scen when the supernatant fraction from $-24 \mathrm{hr}$ nervous tissue was phosphorylated, we assume that the low levels that we subsequently detected arose from a partial solubilization of the labeled EGP-A from the particulate fraction of the $-4 \mathrm{hr}$ nervous tissue. In the converse experiment, the pellet fraction from $-24 \mathrm{hr}$ nervous tissue homogenates was rehomogenized with the supernatant fraction from $-4 \mathrm{hr}$ nervous tissue homogenates, phosphorylated, and separated again by ultracentrifugation. Neither of the EGPs was then found in the pellet fraction and only EGP-A was found in the supernatant.

We assume that the presence of the EGPs in the particulate fraction indicates that they are somehow associated with the cell membranes. To see how tightly they were attached to the membrane, we tried to remove the EGPs from the pellet fraction using a number of different treatments. When $\mathrm{NaCl}$ was added 
Table 1. Distribution of the EGPs and EII-stimulated cGMP levels in the prepupal and pharate adult CNS of Manduca

\begin{tabular}{lllllll} 
Prepupae & \multicolumn{2}{l}{ Pharate adult } \\
\cline { 1 - 2 } \cline { 5 - 7 } Tissue & EGPs & cGMP (\%) & & Tissue & EGPs & cGMP (\%) \\
\hline Brain & + & $174 \pm 12$ & & Brain & - & $272 \pm 33$ \\
Thoracic ganglia & + & $143 \pm 13$ & & Prothoracic ganglion (T1) & - & $181 \pm 19$ \\
Abdominal ganglia & + & $218 \pm 16^{a}$ & & Pterothoracic ganglion (T2-A2) & + & $151 \pm 11$ \\
& & & & Abdominal ganglia (A3-A7/8) & + & $171 \pm 19^{a}$
\end{tabular}

The presence or absence of the EGPs is indicated by + or - . The increase in cGMP levels, measured 15 min after injection, in various parts of the CNS is expressed as the percentage of $\mathrm{EH}$ injected, compared to control animals (taken as $100 \%$; mean \pm SEM of $4-8$ determinations).

"Data taken from Morton and Truman (1985).

(final concentration, $0.5 \mathrm{M}$ ) to the homogenate after the phosphorylation reaction, and ultracentrifugation carried out, a small proportion of EGP-B was solubilized, but no effect was apparent on the distribution of EGP-A. The addition of detergents such as Triton X-100 (final concentration, $0.15 \%$ ) after the phosphorylation reaction also solubilized some of the EGP-B and increased the proportion of EGP-A in the supernatant fraction (Fig. 7, C, D).

\section{The EGPs are not the regulatory subunit of the type II CAMP-} dependent protein kinase

The regulatory subunit of type II cAMP-dependent protein kinase (A-kinase) has a molecular weight of approximately 54 $\mathrm{kDa}$ and is phosphorylated in the presence of cAMP (Beavo and Mumby, 1982). In bovine brain (Lohmann et al., 1980), tick salivary gland (McSwain et al., 1985), and Drosophila heads (Hesse and Marme, 1985), a major cAMP-dependent phosphoprotein with a molecular weight between 52 and $58 \mathrm{kDa}$ was also shown to be a cAMP-binding protein by the incorporation of the photoaffinity ligand 8-azido-cAMP. Both of these properties are consistent with the phosphoproteins' being the regulatory subunit of type II A-kinase.

To determine whether either one of the EGPs was the regulatory subunit of the type II A-kinase, photoaffinity labeling was carried out with 8-azido-cAMP (Fig. 8). In prepupae, $4 \mathrm{hr}$ before ecdysis, one major protein, which specifically bound ${ }^{32} \mathrm{P}-8$-azido-cAMP, was present in abdominal CNS homogenates. This protein was quite distinct from the EGPs, both in molecular weight ( $47 \mathrm{kDa}$ compared to $54 \mathrm{kDa}$ ) and isoelectric point $(4.8$ compared to 5.35-5.85 and 6.45-6.75). A similar cAMP-binding protein was present in homogenates from prepupal and adult brain and abdominal nervous tissuc (results not shown).

\section{Discussion}

Specificity of phosphorylation of the EGPs for CGMP

In the 3 systems studied so far, adult eclosion of Hyalophora cecropia (Truman et al., 1979), intersegmental muscle degeneration in Antheraea polyphemus (Schwartz and Truman, 1984), and pupal ecdysis in Manduca (Morton and Truman, 1985), the action of EH is mediated through cGMP. Therefore, it would be expected that the phosphoproteins involved in the action of EH would also show a clear specificity for cGMP as compared to cAMP. In homogenates of Manduca CNS, this is not the case for the EGPs. cAMP was 180 times more effective at stimulating their phosphorylation than CGMP. In Manduca CNS, the activity of the cAMP-dependent kinase is almost 10 times higher than that of the cGMP-dependent kinase (Morton and Truman,
1986), and thus may be responsible for phosphorylating the EGPs in the presence of cAMP. More comparable levels of A- and G-kinase may be found in subcompartments of the CNS, such as EH target cells.

In intact tissue, in contrast to homogenates, back-phosphorylation studies showed that cGMP was about 40 times more effective than CAMP at stimulating the phosphorylation of the EGPs. This relationship corresponds well with the finding that cGMP is more effective than cAMP at mimicking EH action (Morton and Truman, 1985). The fact that EH stimulates the phosphorylation of the EGPs, and that EH elevates cGMP and not cAMP levels in the CNS (Morton and Truman, 1985), argues that under in vivo conditions cGMP is the second messenger interposed between the $\mathrm{EH}$ receptor and the phosphorylation of the EGPs.

A further difference in the phosphorylation of the EGPs between homogenates and the intact CNS was the time course of phosphorylation. In homogenates, substantial levels of labeled phosphate were incorporated into the EGPs after only $5 \mathrm{~min}$, whereas in the intact CNS, exposure to moderate levels of EH did not result in significant incorporation of phosphate into the EGPs until after $45 \mathrm{~min}$. This delay was seen despite the fact that cGMP levels are elevated within $5 \mathrm{~min}$ after exposure to $\mathrm{EH}$ and remain elevated until after ecdysis (Morton and Truman, 1985). The time course of EGP phosphorylation in the intact CNS corresponds well with the time course of the physiological action of EH; injected EH usually takes longer than 50 min to initiate ecdysis (Truman et al., 1980). These relative times suggest that the phosphorylation of the EGPs is one of the final steps in triggering the physiological actions of $\mathrm{EH}$ in the target cells. The mechanism that results in such a long latency, however, is unknown.

\section{Distribution of the EGPs throughout the CNS}

The EGPs appear to be specifically phosphorylated by EH, so it would be expected that they would be located only in cells that are target cells for EH. The results presented in Table 1 show that these target cells should be found in all parts of the prepupal CNS and in the abdominal and pterothoracic ganglia of the pharate adult. There were no detectable EGPs in the brain and prothoracic ganglia of the pharate adult, but this could be due to the EGPs' being obscured by other phosphoproteins, rather than to their absence. The ability of EH to elevate the levels of cGMP in these parts of the CNS suggests the presence of EH target cells.

In the above discussion we have assumed that the 2 EGPs behave as a single protein. They have the same molecular weight, 
A

B

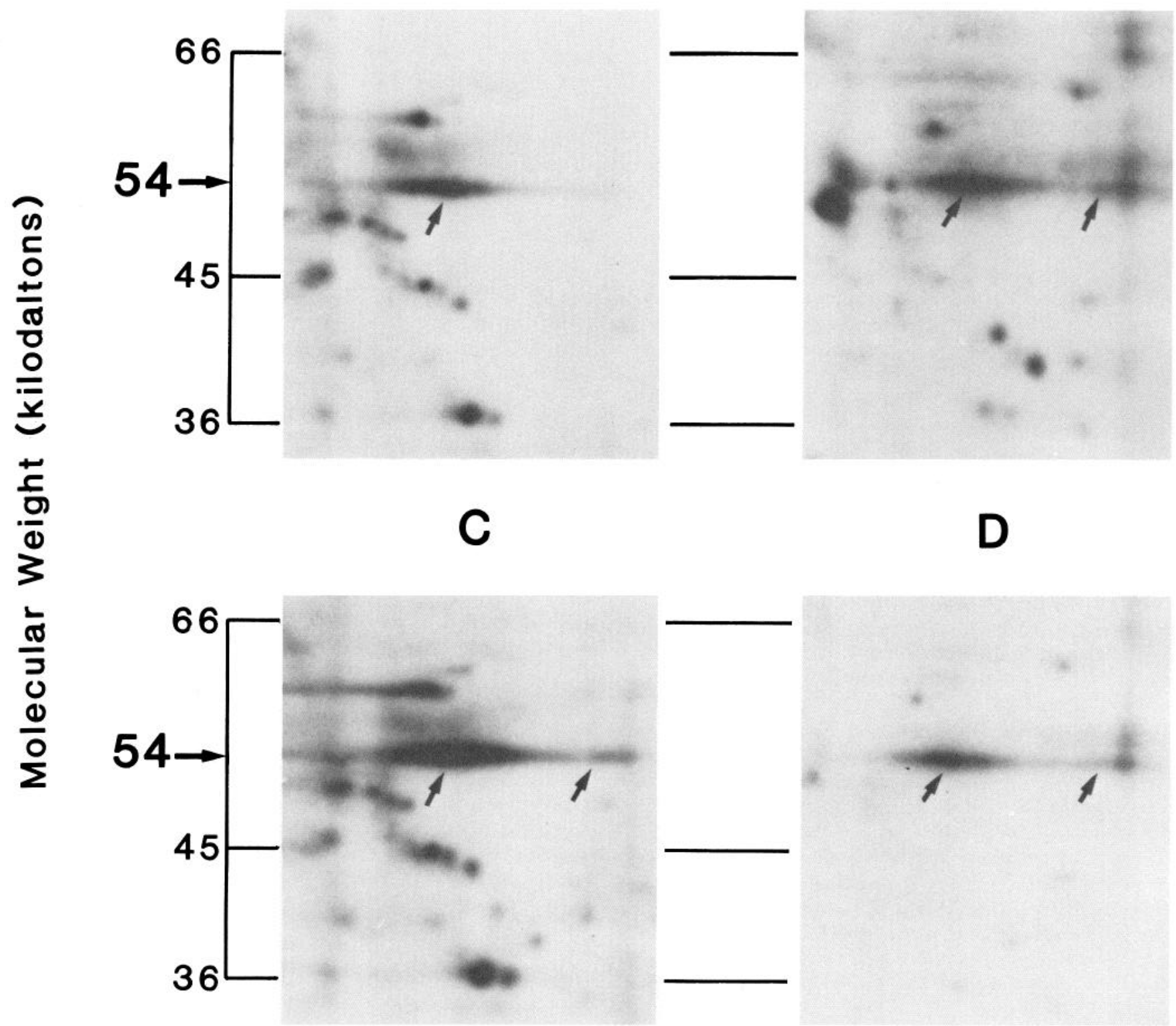

Figure 7. Fluorograms showing the distribution of the EGPs between particulate and soluble fractions of CNS homogenates. Abdominal nervous tissue was removed from animals $4 \mathrm{hr}$ before pupal ecdysis, homogenized, phosphorylated with ${ }^{32} \mathrm{P}-\mathrm{ATP}$ in the presence of $0.1 \mathrm{mM}$ cGMP, and the reaction stopped by placing it on ice. The homogenate was then centrifuged at $100,000 \times g$ for $1 \mathrm{hr}$ at $2^{\circ} \mathrm{C}$, and both supernatant and pellet fractions separated by 2D SDS-PAGE, followed by fluorography. In a parallel experiment, Triton X-100 was added to the homogenate after phosphorylation (final concentration, $0.15 \%$ ), vortexed, and left on ice for $1 \mathrm{hr}$. The homogenate was then centrifuged and separated as before. $A$, Supernatant, $100,000 \times g$ and $(B) 100,000 \times g$ pellet fractions from phosphorylated homogenates of Manduca CNS. $C$, Supernatant, $100,000 \times$ $g$, and $(D) 100,000 \times g$ pellet fractions from phosphorylated homogenates of Manduca CNS in the presence of $0.15 \%$ Triton X-100.

appear at the same time during development, have the same spatial distribution throughout the CNS, and have the same cyclic nucleotide specificity for phosphorylation. However, they have different subcellular distributions: EGP-A is located in both soluble and particulate fractions and EGP-B is located solely in the particulate fraction of homogenates. This differential distribution could be reflected in different functions for each of the EGPs. It is also possible, however, that different posttranslational modifications of the same protein might produce different charged forms, thereby conferring on the proteins different binding properties to membranes, though the 2 proteins would retain similar functions.

\section{Temporal distribution of the EGPs during development}

The EGPs are present before larval, pupal, and adult ecdyses. In the case of larval and pupal ecdyses, their ability to accept labeled phosphate in vitro coincides with the onset of behavioral responsiveness to $\mathrm{EH}$. This is $6 \mathrm{hr}$ before the normal time of larval ecdysis and $8 \mathrm{hr}$ before pupal ecdysis. This close temporal correlation suggests that the lack of responsiveness to $\mathrm{EH}$ in 

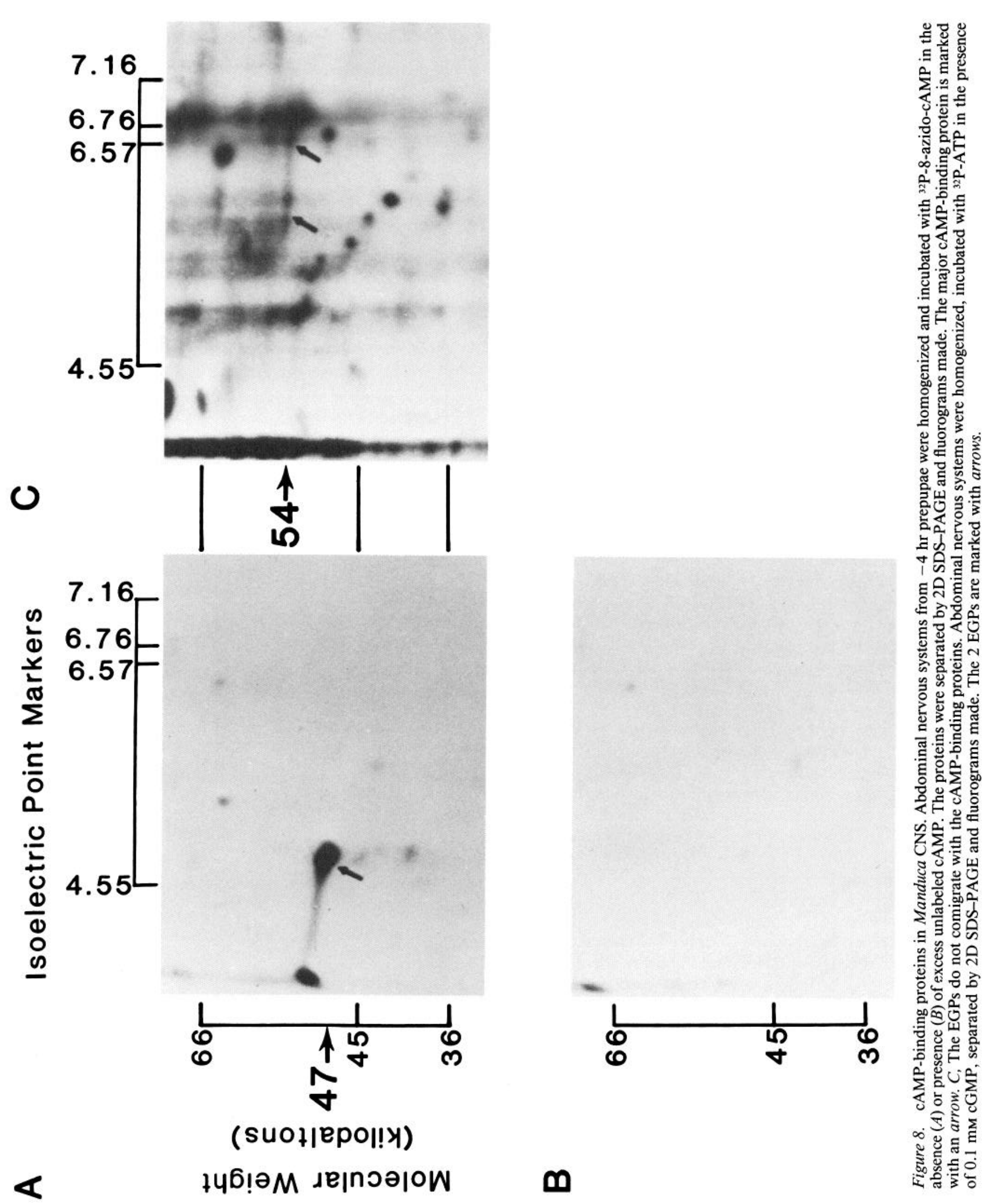
each case is due to the inability to phosphorylate these proteins. Twenty-four hours before pupal ecdysis, the absence of the EGPs on fluorograms could be caused by the absence of the EGPs themselves or by their inability to be phosphorylated. We favor the former hypothesis for 2 reasons. First, the experiments that described swapping the $100,000 \times g$ supernatants and pellets from CNS homogenates of animals 24 and $4 \mathrm{hr}$ before ecdysis show that although the phosphorylating enzymes are present 24 hr before ecdysis, the EGPs are still not phosphorylated. Second, experiments with the protein synthesis inhibitor, cycloheximide, indicate that protein synthesis is necessary for the subsequent appearance of the EGPs on fluorograms. The EGPs are first visible on fluorograms $8 \mathrm{hr}$ before ecdysis. Injections of cycloheximide $10 \mathrm{hr}$ before ecdysis blocked the incorporation of label into the EGPs that were examined $8 \mathrm{hr}$ later. Injection of cycloheximide $6 \mathrm{hr}$ before ecdysis, however, did not prevent incorporation of label into the EGPs (D. B. Morton and J. W. Truman, unpublished observations). The simplest hypothesis regarding these observations is that the EGPs are absent prior to EH sensitivity in the larvae and the pupae. Their de novo synthesis is then initiated at $8-10 \mathrm{hr}$ before ecdysis.

In developing adults, the EGPs are first seen $6 \mathrm{~d}$ before the insect is able to respond physiologically to EH. This raises the question of which step regulates EH sensitivity at adult ecdysis. All known steps in the biochemical cascade of events underlying $\mathrm{EH}$ action (elevation of cGMP levels and phosphorylation of the EGPs) can occur at least $20 \mathrm{hr}$ before EH triggers ecdysis. Thus, at larval and pupal ecdysis the EGPs appear to be both necessary and sufficient for EH action, whereas in the adult they are necessary but not sufficient. The additional factor(s) required for adult ecdysis is (are) not known.

At each stage the ability of the EGPs to accept labeled phosphate under in vitro conditions disappears immediately at ecdysis. As with times prior to pupal ecdysis, this could be due to the absence of the EGPs or to their inability to be phosphorylated. This disappearance of the ability to label the EGPs can be prematurely induced by triggering premature ecdysis with EH or cGMP injection. We suggest that the inability to label the EGPs immediately after each ecdysis is caused by the fact that the EGPs are phosphorylated with endogenous, unlabeled phosphate as a result of the action of endogenous $\mathrm{EH}$ in triggering ecdysis. It is not clear what happens to the EGPs after they have been phosphorylated in vivo. In larval and pupal nervous systems the EGPs cannot be phosphorylated for several days after ecdysis, whereas in the adult, the EGPs can be phosphorylated in vitro by $24 \mathrm{hr}$ after ecdysis. Because our evidence suggests that the EGPs are synthesized prior to each ecdysis, we suggest that at some point after larval and pupal ecdysis, the EGPs are degraded. This does not appear to happen after adult ecdysis. The reason for the EGPs' continued presence in the adult CNS is unknown.

The presence of the EGPs in the very different nervous systems of the larvae, the pupae, and the adult shows that these proteins are not stage-specific. Rather, their appearance is related only to the attainment by the CNS of a specific physiological statc, that of being responsive to the neuropeptide $E H$. As far as we are aware, this is the first example of a regulatory protein that is correlated with a particular type of behavior.

\section{References}

Beavo, J. A., and M. C. Mumby (1982) Cyclic AMP-dependent protein phosphorylation. In Handbook of Experimental Pharmacology, vol.
58 , pt. 2, J. $\Lambda$. Nathanson and J. W. Kebabian, eds., pp. 363-392, Springer-Verlag, New York.

Bell, R. A., and F. A. Joachim (1978) Techniques for rearing laboratory colonies of tobacco hornworms and pink bollworms. Ann. Entomol. Soc. Am. 69: 365-373.

Copenhaver, P. F., and J. W. Truman (1982) The role of the eclosion hormone in larval ecdysis of Manduca sexta. J. Insect Physiol. 28: 695-701.

Drummond, G. I. (1984) Cyclic Nucleotides in the Nervous System, Raven, New York.

Ephrussi, B., and A. W. Beadle (1936) A technique for transplantation for Drosophila. Am. Nat. 70: 218-225.

Forn, J., and P. Greengard (1978) Depolarizing agents and cyclic nucleotides regulate the phosphorylation of specific neuronal proteins in rat cerebral cortex slices. Proc. Natl. Acad. Sci. USA 75: 51955199.

Hesse, J., and D. Marme (1985) A cAMP-binding phosphoprotein in Drosophila heads is similar to the regulatory subunit of the mammalian type II cAMP-dependent protein kinase. Insect Biochem. 15: $835-844$.

Laemmli, U. K. (1970) Cleavage of structural proteins during the assembly of the head of bacteriophage T4. Nature 227:680-685.

Levine, R. B., and J. W. Truman (1983) Peptide activation of a simple circuit. Brain Res. 279: 335-338.

Lincoln, T. M., and J. D. Corbin (1983) Characterisation and biological role of the cGMP-dependent protein kinase. Adv. Cyclic Nucleotide Res. 15: 139-192.

Lingle, C. J., E. Marder, and J. A. Nathanson (1982) The role of cyclic nucleotides in invertebrates. In Handbook of Experimental Pharmacology, vol. 58, pt. 2, J. A. Nathanson and J. W. Kebabian, eds., pp. 787-845, Springer-Verlag, New York.

Lohmann, S. M., U. Walter, and P. Greengard (1980) Identification of endogenous substrate proteins for cAMP-dependent protein kinase in bovine brain. J. Biol. Chem. 255: 9985-9992.

McSwain, J. L., R. C. Essenberg, and J. R. Sauer (1985) Cyclic AMP mediated phosphorylation of endogenous proteins in the salivary glands of the Lone Star tick, Amblyomma ammericana (L). Insect Biochem. 15: 789-802.

Merril, C. R., D. Goldman, and M. L. Van Keuran (1983) Silver staining methods for polyacrilamide gel electrophoresis. Methods Enzymol. 96: 230-239.

Morton, D. B., and J. W. Truman (1985) Steroid regulation of the peptide-mediated increase in cyclic GMP in the ncrvous system of the hawkmoth, Manduca sexta. J. Comp. Physiol. 157: 423-432.

Morton, D. B., and J. W. Truman (1986) Substrate phosphoprotein availability regulates eclosion hormone sensitivity in an insect CNS. Nature 323: 264-267.

Nestler, E. J., and P. Greengard (1984) Protein Phosphorylation in the Nervous System, Wiley, New York.

O'Farrell, P. Z., H. M. Goodman, and P. H. O'Farrell (1977) High resolution two-dimensional electrophoresis of basic as well as acidic proteins. Cell 12: 1133-1142.

Reynolds, S. E., P. H. Taghert, and J. W. Truman (1979) Eclosion hormone and bursicon titres and the onset of hormonal responsiveness during the last day of adult development in Manduca sexta (L). J. Exp. Biol. 78: 77-86.

Rudolph, S. A., and B. K. Krucger (1979) Endogenous protein phosphorylation and dephosphorylation. Adv. Cyclic Nucleotide Res. 10: 107-133.

Schwartz, L. M., and J. W. Truman (1984) Cyclic GMP may serve as a second messenger in peptide-induced muscle degeneration in an insect. Proc. Natl. Acad. Sci. USA 81: 6718-6722.

Steiner, A. L., C. W. Parker, and D. M. Kipnis (1972) Radioimmunoassay for cyclic nucleotides. I. Preparation of antibodies and iodinated cyclic nucleotides. J. Biol. Chem. 247: 1106-1113.

Truman, J. W. (1971) Physiology of insect ecdysis. I. The eclosion behaviour of saturniid moths and its hormonal release. J. Exp. Biol. 54: 805-814.

Truman, J. W. (1978a) Hormonal release of stereotyped motorprogrammes from the isolated nervous system of the Cecropia silkmoth. J. Exp. Biol. 74: 151-174.

Truman, J. W. (1978b) Rhythmic control over endocrine activity in insects. In Comparative Endocrinology, P. J. Gaillard and H. H. Boer, eds., pp. 123-136, Elsevier, New York.

Truman, J. W., S. M. Mumby, and S. K. Welch (1979) Involvement 
of cGMP in the release of stereotyped behavior patterns in moths by a peptide hormone. J. Exp. Biol. 84: 201-212.

Truman, J. W., P. H. Taghert, and S. E. Reynolds (1980) Physiology of pupal ecdysis in the tobacco hornworm, Manduca sexta. I. Evi- dence for control by eclosion hormone. J. Exp. Biol. 88: 327-337.

Walter, U., and P. Greengard (1983) Photoaffinity labeling of the regulatory subunit of cAMP-dependent protein kinase. Methods Enzymol. 94: 154-162. 